\title{
Mechanical Simulation and Numerical Deduction for Volume Expansive-Prone Slag in a Rigid Matrix
}

\author{
George C. Wang 1,* \\ ${ }^{1}$ Department of Construction Management, College of Engineering and Technology, East Carolina University, \\ Greenville, NC 27858-4353, USA \\ *Correspondence: wangg@ecu.edu; Tel.: (+1-252-737-1887)
}

\begin{abstract}
As the coproduct of steelmaking, steelmaking slag, volumetrically expansive-prone without treatment, has been satisfactorily used as an aggregate base course material in highway construction. Although numerous technical reports and papers have revealed that steel slag aggreged using in rigid matrixes, the end product, paving block, non-structural concrete, for example, possesses superb strength and durability properties, the application of steel slag aggregate as a concrete aggregate is currently prohibited in highway construction. Naturally, researchers explore the practicality of use of steel slag, how to connect the laboratory experiment results to the end-product behavior, and further convert the research results into real construction? For all nontraditional or secondary materials utilization, the procedure of laboratory material examination, lab and field trial test are critical. To generalize the utilization, usability criteria establishment is necessary. This paper tries to use step-by-step method and plain language to explain how the volumetrically expansion can be simulated in lab testing apparatus, and based on the model, the mathematical deduction can result in a numerical usability criterion for steel slag use as a coarse aggregate in concrete (a rigid material). Therefore the paper is composed four main parts, laboratory test methods to examine the expansion force resulted from steel slag; converting the measured expansion force in a given volume of mass aggregate to the expansion (body) force of a single particle; modeling of slag and end material disruption; and a usability criterion from numerical deduction for the use of expansive-prone coarse slag in concrete or other rigid matrices. The paper provides the solutions to answer the above questions. Through the mathematical and mechanical modeling, provides the potential criteria that could result in specifications and guidance establishment for broad volumetric expansive-prone slags.
\end{abstract}

Keywords: steel slag; concrete; expansion force; rigid matrix

\section{Introduction}

The original impetus of using steel slag to replace natural aggregate in cement-based material is because the superb physical and mechanical properties. Also, environmental protection and natural resource conservation, and sustainable development of the society require using nontraditional, secondary or recycled materials in construction [1-3].

The significant benefits of using slag, like using other recycled material, can be measured from different aspects. These include substantial reduction in processing natural material thus environmental pollution protection and reduction in energy required related with the winning of natural materials. The use of recycled materials in different quantity and blend use with other materials could result in modification and alteration of the end-products' physical, chemical, mineral, mechanical properties that traditional materials may not possess that can be used specific applications.

The utilization various metalogical slag at a full scale has become increasingly imperative for the sustainable development of our society including environment, economic, and societal aspects. 
Researchers and engineers have conducted research and application in using coarse steel slag as a concrete aggregate in the past decades. Results reported have shown that portland cement concrete (non-structural) and building units with steel slag as aggregate have good strength related properties [4-12], or in special uses, radiation shielding, for instance [13-15]. The specific characteristics of concrete with slag aggregate are originated from the unique inherent properties of steel slag. It is well known that the coarse aggregate's geometric shape, surface texture, chemical activity and hydrophilicity influence significantly on the bonding strength between aggregate and cement paste, which is the main contribution to the strength of concrete. Figure 1 illustrates the scenarios of impacts and effects from in different surface texture, particle shape and disrupt position. Assuaging case (a) in Figure 1 is 1 representing the bond between aggregate and cement paste, other cases are listed. It can be seen aggregate particles with rough surfaces have higher bonding strength. Crushed slag has rough texture that improves the mechanical interlocking the affinity of aggregate for moisture and cement paste. Processed steel slag aggregate has the good properties required for gaining higher strength of concrete.

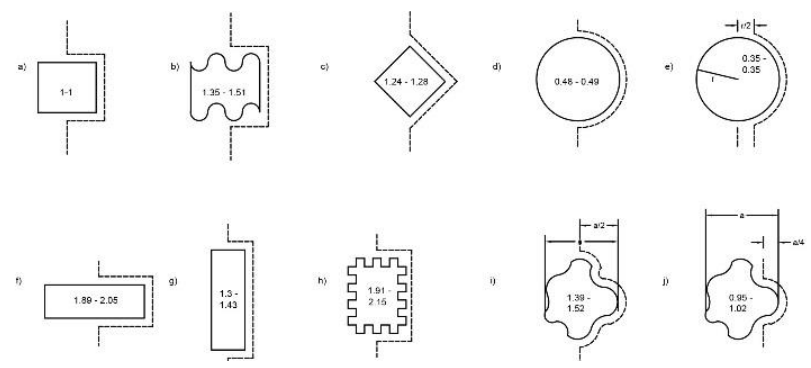

Figure 1. Ratio comparison of bonding strength between various aggregates and cement paste.

Great amount of work has been done simply by replacing natural aggregate by steel slag aggregate and received good strength results. However, the phenomena have less support by thorough characterization and performance testing, which is the reason why the use of slag in concrete has paused in laboratory status. Steelmaking slag, actually, is presently permitted to be used in highway construction projects as a concrete aggregate, although it has been used in some projects in other countries [16-18]. One of the reasons is because of lack of quantified work on slag itself and relating slag to the properties of the matrix where slag is used in. It is important to quantify the expansion potential related properties and its relationship with the mechanical behavior in cementbased matrix.

\section{The Questions need to be Resolved}

From the observations from laboratory's experiments, some steel slag concrete, performed well under normal and rigorous testing conditions, for example, under the autoclave condition and longterm water curing, gained similar results or exceeded to ordinary portland cement concrete. So the questions have been put forward and need to be resolved include: (i) what is the minimum requirement in terms of expansion for a single expansive slag particle be safely used as a coarse aggregate in cement-based matrix? (ii) how to measure slag's volumetric stability and expansion that can be used to evaluate a slag suitability for use in rigid matrix? (iii) can a disruption model can be set to better describe the disrupture mechanism of steel slag in concrete considering concrete is a structural sensitive material, which means a single particle could result in the failure of the concrete structure (iv) relate any quantitative measurements of expansion of a slag particle and the concrete constraining ability with steel slag coarse aggregate. The expansion of steel slag should be investigated in a deeper level. In this study the methods to determine the expansion of slag are different from conventional methods, i.e. volume expansion by ASTM, rather a force resulted from bulk volume of steel slag is developed. The expansion force generated by an expansive slag particle must be deduced which can be used in establishing criteria for safe use slag in concrete. 


\section{Body Force or Expansion Force}

Different from the use in unbound conditions like steel slag in a granular base course, concrete is a rigid material, which performs differently from aggregate base course materials. It was planned conduct a laboratory investigation to get the expansion force generated by a steel slag, a given volume of slag sample and a single particle. If a body force by a single slag particle is known, it will be possible to establish a disruption mechanism of the concrete.

The three-dimensional expansion force per unit volume, $\sigma_{e}$, can be called body force from a given bulk volume of slag measured from the force in a universal testing machine, expressed as Pe. Volume expansion (volume changes, \%) is not used. The purpose of the $\sigma_{e}$, is to determine the plane or tensile stress generated resulted from expansion force, in other words, the maximum or dangerous tensile stress on an expansive slag particle, $\sigma_{\mathrm{t}}\left(\mathrm{N} / \mathrm{m}^{2}\right)$ that can be used to relate to the allowable tensile stress, $\mathrm{F}$ of hardened cement paste. The expansion force produced by a single unstable slag particle or a volume of mass slag particles are different. The first step is to determine the bulk expansion force. and the expansion force is directly related to the total volume of the particles. It can be seen the logic relations here are:

How to measure the expansion force of bulk slag sample; how to calculate the expansion force from a single particle; how to convert the expansion force from a single particle into a tensile stress; and how to establish a usability criterion.

It is critical to understand the expansion force from a single particle as concrete is structurally sensitive. The two test methods presented here answer the questions. A mathematical modeling and laboratory experiments will provide the answers to other questions.

Assume that a slag sample is placed in a steel mold (rigid) which can freely expand upwards, i.e., in one direction, volume expansion can be measure if it happens. If the slag cannot expand freely in any direction, i.e., it is completely confined, an internal expansion force will be generated from the confined slag in the mold. The measurable expansion force is the function of the volume of a given slag with a given unstable chemical and/or mineral composition, $\mathrm{f}-\mathrm{CaO}$ and/or periclase, for instance. The larger the volume of the mold, the higher the expansion force. The expansion force is $\mathrm{Pe}$ as indicated above. It is the resultant force by the slag sample confined in the rigid mold. The magnitude of the force is directly proportional to the volume of expansive slag sample.

The above volume expansion force in a unit volume, $\sigma_{e}$, can be defined as $\mathrm{Pe} / \mathrm{V}$. It is directly proportional to the volume expansion (\%) which can be measured, but it is note measured in this study. Thus, it is clear that there exit the relationships (proportionality constant):

Resultant or total expansion force $(\mathrm{Pe}) \propto$ Volume of slag sample (V)

Unit volume expansion force $\left(\sigma_{e}\right) \propto$ Volumetric expansion of slag sample (\%)

The total expansion force $\mathrm{P}_{\mathrm{e}}$ can be calculated as discussed below. The expansion force is constant at any point within the volume of slag sample. The greater the volume, the greater the expansion force. However, it is noted $\sigma_{\mathrm{e}}$ is constant as it not related to volume. It must be noted that this only applies to the mass slag samples in a constrained condition. Single slag particles are different case. Apparently, the three-dimensional expansion force is uniquely suitable for expansion of steel slag. This is totally different from compression or compressive stress and tension or tensile stress.

Figure 2 illustrate the total expansion force is dependable to the volume of slag sample, that is to say, to the size of the rigid mole or three-dimensional unit. Figure 2 a), shows a slag is contained in separate rigid molds with the identical diameter and different heights, $\mathrm{T}_{2}>\mathrm{T}_{1}$. Figure $2 \mathrm{~b}$ ) shows two rigid molds have the identical heights and different diameters, $\mathrm{T}_{2}{ }^{\prime}>\mathrm{T}_{1}{ }^{\prime}$. Figure 2 shows $\mathrm{T}$ is the total expansion force experimentally measurable on the cross-sectional area. 

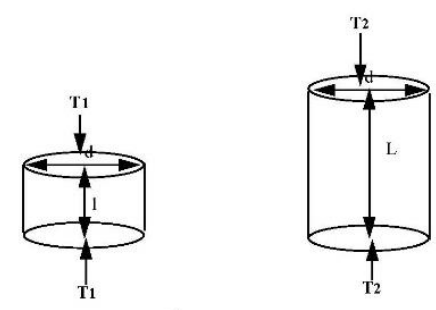

$\mathrm{T} 2>\mathrm{T} 1$
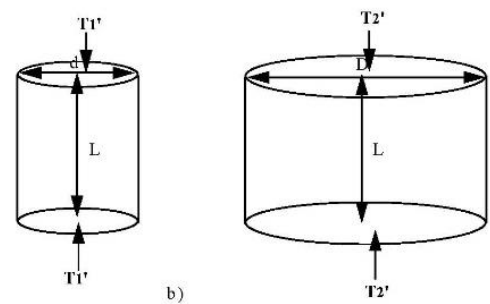

Figure 2. Two rigid mold with different sizes.

The expansion force is totally different from compressive stress from which is generated from an external force. It is an external force causes compressive stress; while it is the slag itself generates expansion force. Distinguishing the two different forces is necessary to analyze the expansion force.

\subsection{Differences of an expansion body and a body undergoing compression}

\subsubsection{Scenario A}

In Figure 3 a), for a solid matter with a given volume and constant thickness, undergoing expansion, the maximum load on the right is larger in magnitude than load on the left when the surface is restrained and exerts compression. The maximum load is independent of the volume of the specimen and is only related to the loading area. For a mass of steel slag compacted in a stiff mold, however, the expansion force produced by the mass of steel slag is variable dependent on the volume as shown in Figure 2. However, the expansion force measured from any cross-sectional area of the steel slag sample is a constant value as shown in Figure $3 \mathrm{~b}$ ). Here, expansion force can be measured by means of load cell and rigid mold by multiplying 6 , as illustrated below.

In order to explain the latter, i.e. the expansion force of steel slag, a model of steel slag particles in the mold is set up as shown in Figure 4. It is assumed that the steel slag particles are saw-cut to cubes contained within a rigid mold.

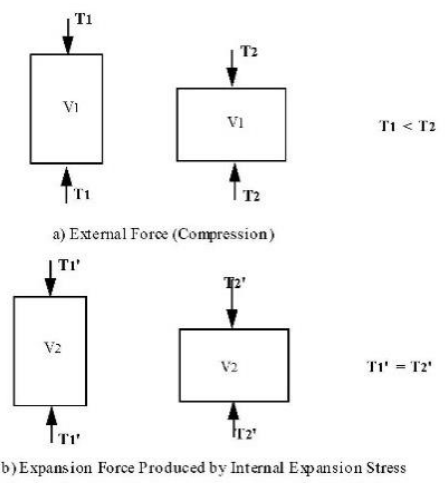

Figure 3. The difference of expansion force and compression. 


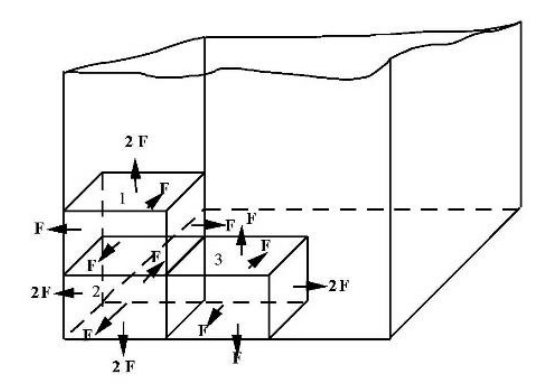

Figure 4. A rigid container containing expansive cubes.

Figure 4 shows how the expansive cubes (simulating to slag particles) are analyzed. The body forces from cubes 1 and 2 in vertical direction are 2F. Assume the surface area is S, the "surface stress" is $2 \mathrm{~F} / \mathrm{S}$. The body forces from cubes 2 and 3 are the same in the horizontal direction. It is also noted that the body force from cube 1 in the horizontal direction is F, the "surface stress" is F/S. This implies that, although the resultant side surface expansion force $\mathrm{T}$ is constant, the force per unit area is varied subject to position in the container and is proportional to the number of the cubes (expansive slag particles) within that area, or, to the total length of the of the cubes (steel slag particles).

\subsubsection{Scenario B}

For a uniaxial cube, a unit element, carrying compressive stress, the stresses on the three directions are normally not equal (Figure 5).

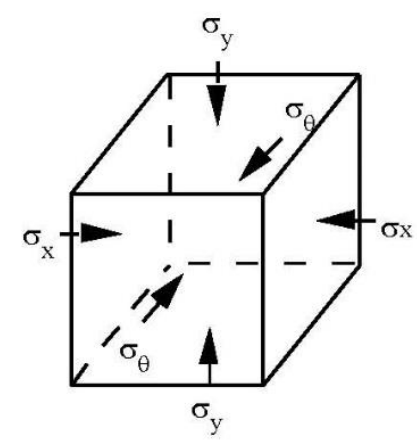

Figure 5. A unit element with stresses from three direction.

$$
\begin{aligned}
& \varepsilon_{,}=\mathrm{k}\left[\begin{array}{ccc}
1 & -\mu & -\mu \\
-\mu & 1 & -\mu \\
-\mu & -\mu & 1
\end{array}\right] ; \sigma^{\prime} \\
& \varepsilon_{\mathrm{x}}=\mathrm{k}\left[\sigma_{\mathrm{x}}-\mu \sigma_{\mathrm{y}}-\mu \sigma_{\theta}\right]=0 \\
& \varepsilon_{\mathrm{y}}=\mathrm{k}\left[-\mu \sigma_{\mathrm{x}}+\sigma_{\mathrm{y}}-\mu \sigma_{\theta}\right]=0 \\
& \varepsilon_{\theta}=\mathrm{k}\left[-\mu \sigma_{\mathrm{x}}-\mu \sigma_{\mathrm{y}}+\sigma_{\theta}\right]=0 \\
& \left.\sigma_{\mathrm{y}}\left(1-\mu^{2}\right)=\mu(1+\mu)\right) \sigma_{\mathrm{x}} \\
& \sigma_{\mathrm{y}}=\frac{\mu(1+\mu)}{1-\mu^{2}} \sigma_{\mathrm{x}} \\
& \because \quad \mu(1+\mu) \neq 1-\mu^{2} \\
& \therefore \quad \sigma_{\mathrm{x}} \neq \sigma_{\mathrm{y}}
\end{aligned}
$$

Similarly, 


$$
\sigma_{\mathrm{y}} \neq \sigma_{\theta}
$$

Totally different from the scenarios above, the body force is three dimensional and have the same value at any point.

Thus, the calculation of the resultant expansion (body) force, $\mathrm{P}_{\mathrm{e}}$, by a given volume of slag sample, and the expansion force in a unit volume, $\sigma$ e. are needed.

Pe can be calculated according to the body force test (Figure 8). First, it is assumed that the surface expansion force $\mathrm{T}$ can be partially determined from the dial gauge reading obtained in the test.

The dimension of the mold is $128 \mathrm{H} \times 150 \mathrm{D}(\mathrm{mm})$, and the volume $\mathrm{V}_{c}=2.26 \times 106 \mathrm{~mm}^{3}$. $\mathrm{T}$ can be measured from the load cell fixed on the movable plate on the top of the mold. Unfortunately, it is not possible to determine $\sigma_{e}$ from $\mathrm{T} / \mathrm{V}$. This is because $\mathrm{T}$ is the force acting on the top surface area, it is not the resultant (total) expansion force of the entire volume of the expansive slag sample, becasue expansive slag samples expands in all directions.

It is also impossible to use T/A to calculate the two-dimensional tensile stress $\sigma \mathrm{t}$. This is because the volume of slag sample includes both solid slag particles and voids. Area A does not represent the true area occupied by the sample. Considering slag samples confined in two cylinders with the same diameter, but with different heights, the body force $\mathrm{T}_{1} \neq \mathrm{T}_{2}$ (Figure 2 ). If two dimensions are used, tensile stress due to expansion force $\sigma_{t}=T / A$, the stress $\sigma_{t}$ would be different for the same slag sample with the dimensional size change.

Therefore, the value of T/A has no relation tensile stress or tension force from a steel slag particles which could lead the cracking. Tt only represents the expansion force from one dimension.

The total body force $P_{e}$ is generated over the surface area, i.e., $P_{e}$ is the summation of all body force from all individual particles (T). In Figure 4, this assumption is reasonable as the body (expansion) force from each individual slag particle (if the individual particle is unstable) will be transmitted to the particle's outer surface. It can be seen that the surface expansion force is $2 \mathrm{~T}$. The expansion force per unit area is called the virtual expansion force $\sigma_{\mathrm{v}}$ and is calculated by T/A $\left(\mathrm{N} / \mathrm{m}^{2}\right)$. From the analysis, $\sigma_{v}$ is related to the length of the sample and is not the same from surface to surface. The virtual expansion stresses on the top and base are the same; however, the virtual expansion stresses on the side areas, $\sigma_{\mathrm{vs}}$, are different from that on the top area. The side virtual expansion stresses, $\sigma_{\mathrm{vs}}$, is proportional to that on the top or base area, i.e.,

$$
\begin{aligned}
& \frac{\sigma_{v}}{L}=\frac{\sigma_{v s}}{D} \\
& \sigma_{v}=\frac{T}{A} \\
& \sigma_{v s}=\sigma_{v} \times \frac{D}{L} \\
& T_{s}=\sigma_{v s} \times A_{s} \\
& P_{e}=2 T+T_{s} \\
& P_{e}=2 T+\frac{T}{A} \times \frac{D}{L} \times \pi D L= \\
& =2 T+\frac{4 T D}{\pi D^{2} L} \times \pi D L=6 T
\end{aligned}
$$

This implies that the total expansion stress $P_{e}$ can be determined from the test by $P_{e}$ being equal to six times of the force, readings from the test on the top area of the container or mold. This is independent from the measured surface area. This implies that if two containers are used, one and two, having the same volume with a $150 \mathrm{~mm}$ diameter, container two with a $200 \mathrm{~mm}$ diameter, the force $\mathrm{T}$ measured for one and two are the the same and the resultant or total expansion forces are 6T. 


\section{Determine the Expansion Force by Two Innovative Tests}

\subsection{Particle Disruption Ratio Test}

Tensile stress or stress intensity leads concrete, the structure sensitive material failure. The unstable particle(s) contributes the structure failure, not the stable particles. Figure 6 explain this situation. One unstable slag particle (left side) could cause the rigid matrix's failure; the same unstable particle with stable particles may also cause the damage (right side). Therefore, unstable particles control the rigid body's ultimate stability or failure. Therefore, there is a need to find how many unstable particles in a given number of aggregate particles. The test developed is called Particle Disruption Ratio Test showing in Figure 7. The value, i.e., disruption ratio (R) will be used to evaluate the potential failure later.
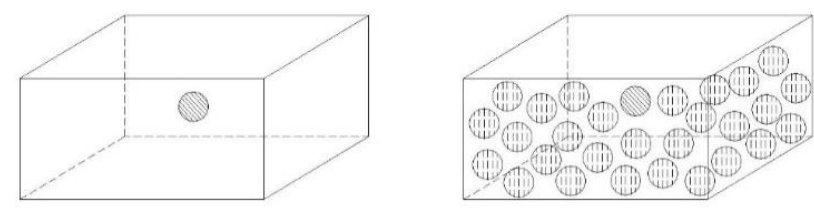

stable steel slag particle

unstable steel slag particle

Figure 6. Single expansive slag particle can lead the concrete failure.

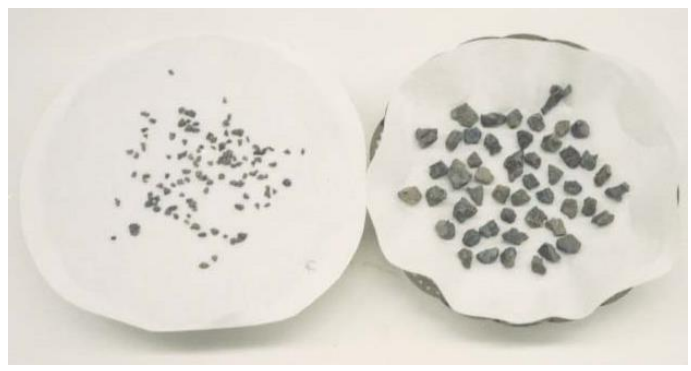

Figure 7. Coarse slag particles after autoclave examination.

4.2. Bulk body force and expansion force by a single unstable slag particle test

A universal testing machine is used for this test shown below (Figure 8).

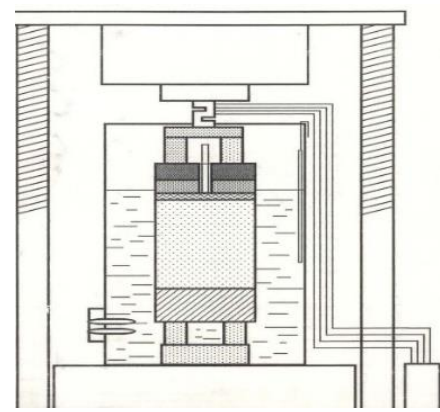

Figure 8. The apparatus to check the total expansion force.

Figure 9 gives the embryonic form of a portable body force tester. It is the preliminary form of the apparatus being developed. This device simulates the test by using the universal test machine shown above. 
Bulk expansion (body) force $\mathrm{Pe}_{\mathrm{e}}(\mathrm{N})$, of slag aggregate sample can be determined which is a three dimensional body force per unit volume, $\sigma_{e}\left(\mathrm{~N} / \mathrm{mm}^{3}\right)$. The volumetric body force per unit volume, $\sigma_{e}$, can be calculated by $\mathrm{Pe} / \mathrm{V}$.

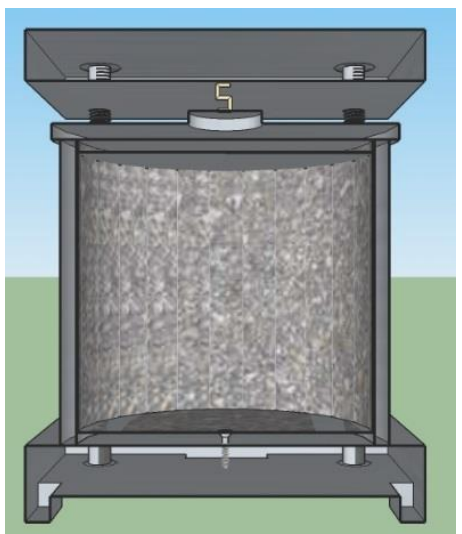

Figure 9. A concept of portable expansion force testing mold.

From the calculation and reduction, the body force produced by one unstable particle is:

$$
F_{s s}=f_{e u s} V_{s s}=\frac{f_{e x} \pi d^{3}}{6 R \Phi}=\frac{F_{e x} \pi d^{3}}{6 V_{s l} R \Phi}
$$

Here $F_{s s}$ is the body force produced by one slag particle, $(\mathrm{N})$; $f_{\text {eus }}$ is the body force of slag particle in concrete, $\left(\mathrm{N} / \mathrm{m}^{3}\right) ; \mathrm{V}_{\text {ss }}$ is the volume of slag particle, $\left(\frac{\pi d^{3}}{6}\right)\left(\mathrm{m}^{3}\right) ; \mathrm{d}$ is the nominal particle size of the steel slag aggregate, $(\mathrm{m}) ; \mathrm{R}$ is disruption ratio, $(\%) ; \mathrm{f}_{\mathrm{ex}}$ is the expansion force generated by a dense compacted steel slag in a unit volume, $\left(\mathrm{N} / \mathrm{m}^{3}\right) ; \mathrm{V}_{\mathrm{sl}}$ is the volume of compacted sample, $\left(\mathrm{m}^{3}\right) ; \Phi$ is a constant the maximum solid volume of spheres in compacted condition $(67 \%)$. The equation is illegal when $\mathrm{R}=0$, i.e., when the steel slag particles are volumetric stable (disruption ratio is zero).

\section{Disruption Model that leads a Usability Criterion}

It can be seen below that $F_{s s}$ is distributed in a slag particle which converts the plane stress $F_{s s}$ to the maximum dangerous stress in a particular.

It is critical to find the plane stress resulted from the volume expansion of one slag particle, or to say, the maximum tensile stress generated by or on an unstable slag particle, $\sigma_{t}\left(\mathrm{~N} / \mathrm{m}^{2}\right)$ which is useful to set up the relation between the stress and concrete's (or cement-based matrix) allowable tensile stress, F. When steel slag is used as a coarse aggregate in concrete, the volume stability is basically controlled by the allowable stress of the matrix materials, cement paste, and the expansion stress of a slag particle. A usability criterion for steel slag use in constrained matrix can be established.

From the above-mentioned modeling and assumption, it is possible to derive the relations shown below. Here reasonably three assumptions are made for simplification: (i) slag particle is spherical; (ii) slag particles with a single particle size or uniformly graded are used (for simplification of the basic model); (iii) unstable slag particle breakage results in the breaking of the rigid or mortar matrix based on the structural sensitivity. The aggregate tensile splitting stress or force is generated from the total or resultant force of normal volume stress and can be obtained by mathematically integrating the expansion force per unit volume in the volume of the half particle (Figure 10). 


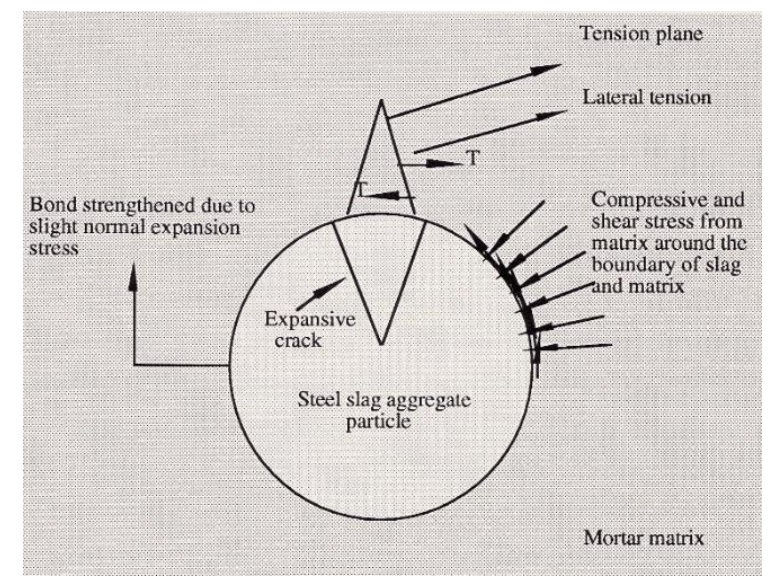

Figure 10. Expansive force failure model.

The tensile splitting force by the bad particle is generated from the total or resultant force of normal stress, and can be obtained by integrating the expansion force per unit volume in the volume of the half particle:

$$
\begin{gathered}
P_{t}=\sigma_{e u v} \iiint_{V} d v=\sigma_{e u v} \int_{0}^{\pi} \sin \theta \sin \theta d \theta \int_{0}^{\pi} d \varphi \int_{0}^{d / 2} r^{2} d r=\frac{\pi^{2} d^{3}}{48} \sigma_{e u v} \\
P_{t}=\frac{\pi^{2} d^{3} \sigma_{e}}{48 R \Phi}
\end{gathered}
$$

The tension stress which acts on the diametrical section of a particle can be calculated by:

$$
\sigma_{t}=\frac{P_{t}}{A_{m s}}=\frac{\pi d \sigma_{e}}{12 R \Phi}
$$

In Equation (19, Ams denotes the area on a diameter of a slag particle. This force may produce a normal stress in the matrix in the condition of uniform expansion. Therefore, the normal stress acting on the surface of the steel slag particle will be

$$
\sigma_{n}=\frac{P_{e s}}{A_{s}}=\frac{\sigma_{e} d}{6 R \Phi}
$$

In Equation 20, $A_{s}$ is the whole surface area of a steel slag particle, (equals $\pi \mathrm{d}^{2}$ ). It shows that the tensile stress at is larger than the normal stress $\sigma_{n}$. Therefore, the maximum allowable dangerous stress is controlled by the tension stress $\sigma$.

$$
\begin{aligned}
& \sigma \mathrm{d}=\mathrm{k} \sigma \mathrm{t} \leq[\sigma], \text { i.e. } \\
& \sigma_{d}=k \frac{\pi d \sigma_{e}}{12 R \Phi} \leq[\sigma]
\end{aligned}
$$$$
\text { (21) or }
$$

\section{Testing and Results}

Initial laboratory tests have been conducted to verify

- the maximum expansion force produced by bulk slag samples and a single steel slag particle with a given particle size;

- (ii) particle disruption ratio as shown in Table 1; and

- the volumetric stability of portland cement concrete containing the steel slag samples as an coarse aggregate. 
Table 1. Disruption ratio and expansion force readings for steel slag samples.

\begin{tabular}{|c|c|c|c|c|c|c|}
\hline & \multicolumn{2}{|c|}{ BOF-1 } & \multicolumn{2}{|c|}{ BOF-2 } & \multicolumn{2}{|c|}{ BOF-3 } \\
\hline $\begin{array}{c}\text { Disruption } \\
\text { ratio } \\
R(\%)\end{array}$ & \multicolumn{2}{|c|}{3} & \multicolumn{2}{|c|}{2} & \multicolumn{2}{|c|}{5} \\
\hline $\begin{array}{l}\text { Nominal } \\
\text { size }(\mathrm{mm})\end{array}$ & \multicolumn{2}{|c|}{20} & \multicolumn{2}{|c|}{20} & \multicolumn{2}{|c|}{20} \\
\hline $\begin{array}{c}\text { Testing } \\
\text { days }\end{array}$ & $\begin{array}{l}\text { Expansion } \\
\text { force, } F_{e x} \\
(\mathrm{~N})\end{array}$ & $\begin{array}{l}\text { Expansion } \\
\text { force on a } \\
\text { single } \\
\text { particle } \\
\text { (N) }\end{array}$ & $\begin{array}{l}\text { Expansion } \\
\text { Force, } F_{e x} \\
(\mathrm{~N})\end{array}$ & $\begin{array}{l}\text { Expansion } \\
\text { force on a } \\
\text { single } \\
\text { particle } \\
\text { (N) }\end{array}$ & $\begin{array}{l}\text { Expansion } \\
\text { Force, } F_{e x} \\
(\mathrm{~N})\end{array}$ & $\begin{array}{l}\text { Expansion } \\
\text { force on a } \\
\text { single } \\
\text { particle } \\
\text { (N) }\end{array}$ \\
\hline 1 & 31 & 3 & 375 & 52 & 479 & 26 \\
\hline 2 & 120 & 11 & 549 & 76 & 562 & 31 \\
\hline 3 & 230 & 21 & 723 & 99 & 843 & 47 \\
\hline 4 & 348 & 32 & 825 & 114 & 1120 & 62 \\
\hline 5 & 472 & 43 & 1011 & 140 & 1394 & 77 \\
\hline 6 & 510 & 47 & 1329 & 183 & 1780 & 98 \\
\hline 7 & 652 & 60 & 1665 & 230 & 2146 & 119 \\
\hline 8 & 1023 & 94 & 1971 & 272 & 3573 & 196 \\
\hline 9 & 1464 & 135 & 2301 & 318 & 6680 & 369 \\
\hline 10 & 1896 & 174 & 2637 & 364 & 9600 & 530 \\
\hline 11 & 2430 & 224 & 3237 & 446 & 8500 & 470 \\
\hline 12 & 2876 & 265 & 3573 & 493 & 10650 & 588 \\
\hline 13 & 3452 & 318 & 4023 & 556 & 13680 & 756 \\
\hline 14 & 4231 & 397 & 4023 & 556 & 15884 & 878 \\
\hline 15 & 4937 & 454 & 4021 & 555 & 18054 & 998 \\
\hline 16 & 5830 & 536 & & & 20049 & 1109 \\
\hline 17 & 6240 & 574 & & & 22870 & 1265 \\
\hline 18 & 7420 & 682 & & & 23560 & 1303 \\
\hline 19 & 8754 & 806 & & & 25500 & 1410 \\
\hline 20 & 8751 & 805 & & & 26780 & 1481 \\
\hline 23 & & & & & 28994 & 1603 \\
\hline 26 & & & & & 29100 & 1609 \\
\hline
\end{tabular}

Concrete specimens were cast containing steel slag samples of BOF-1, BOF-2 and BOF-3 coarse aggregate. As well known, the strength properties of the slag concrete are very competitive to natural aggregate concrete. The volume stability showed excellent after three hours autoclave testing at 357 $\mathrm{kPa}, 137^{\circ} \mathrm{C}$, for the concrete cylinders containing BOF-1 and BOF-2 samples. The concrete having BOF-3 slag indicated surface pop-out although the autoclave testing result is marginally acceptable.

Table 1 shows that the maximum expansion force produced from single steel slag particles for BOF-1, BOF-2 and BOF-3 are $806 \mathrm{~N}, 556 \mathrm{~N}$ and $1609 \mathrm{~N}$, respectively. The expansion forces produced by BOF-1 and BOF-2 have no signs of disrupt and unacceptable surface distress under the same rigorous autoclave testing conditions. However, the concrete having BOF-3 slag with maximum expansion force 1,609 $\mathrm{N}$ showed surface pop-outs. An inherent relationship between the allowable 
stress of rigid matrix, such as portland cement mortar and the maximum stress of a bad slag particle. Table 2 shows the expansion force at 21 days (become stable) of a steel slag sample.

Table 2. Total expansive force reading $(T)$.

\begin{tabular}{cccccccc}
\hline Age & 1-day & 2-day & 3-day & 4-day & 5-day & 6-day & 7-day \\
\hline $\begin{array}{c}\text { Expansion } \\
\text { force (N) }\end{array}$ & 30 & 120 & 230 & 348 & 472 & 510 & 654 \\
Age & 8-day & 9-day & 10-day & 11-day & 12-day & 13-day & 14-day \\
$\begin{array}{c}\text { Expansion } \\
\text { force (N) }\end{array}$ & 789 & 1023 & 1460 & 1896 & 2430 & 2876 & 3452 \\
Age & 15-day & 16-day & 17-day & 18-day & 19-day & 20-day & 21-day \\
Expansion & 4231 & 4937 & 5830 & 6240 & 7420 & 8754 & 8750 \\
force (N) & & & & & & & \\
\hline
\end{tabular}

Suppose to use the steel slag as an aggregate in concrete and that the cement to be used is Type I having an allowable tension stress of $2 \mathrm{MPa}, 3.2 \mathrm{MPa}$ and $4.5 \mathrm{MPa}$ at 3 days, 7 days and 28 days respectively. Using a factor of safety $(\mathrm{k}) 1.5$, the calculation can tell if this slag can be used in the concrete.

The total expansion force will be six times the dial gauge readings, $\mathrm{P}_{\mathrm{e}}=6 \mathrm{~T}$, where $\mathrm{T}$ is the expansion force acting on the top surface of the sample,

At 28 days, the dangerous stress will be:

$\sigma_{d}=k \frac{\pi d \sigma_{e}}{12 R \Phi}=\frac{1.5 \times \pi \times 0.02 \times 8750 \times 6 \times 10^{6}}{12 \times 0.03 \times 0.67 \times 2260}=9.07 \mathrm{MPa}>[\sigma]=4.5 \mathrm{MPa}$

Therefore, the given sample should not be used in concrete. If used, the dangerous stress generated from the expansion stress of the slag at each age should be less than the allowable stress of cement paste at the corresponding ages. If this situation exists, it can be said that the utilization of the steel slag as a coarse aggregate in the cement matrix is safe.

The second $16 \mathrm{~mm}$ steel slag sample received the maximum expansion force occurred at 13 days, 4023.6 Newton. The dangerous stress is given by Equation 22:

$$
\sigma_{d}=k \frac{\pi d \sigma_{d}}{12 R \Phi}=\frac{1.5 \pi \times 0.016 \times 4023.6 \times 10^{6}}{12 \times 0.03 \times 0.67 \times 2260}=0.56 \mathrm{MPa}<[\sigma]=3.2 \mathrm{MPa}
$$

The dangerous stress is less that the allowable stress of the subject cement at 7 days, therefore, the slag sample can be acceptable used in the given concrete.

\section{Conclusion and Remarks}

The utilization criteria for the use of steelmaking slag as a coarse aggregate in portland cement concrete is established from the experimental determining expansion stress; calculating the expansion stress; establishing the disruption model of slag in concrete and theoretical development of criterion.

From simulation, theoretical analysis and testing, the following conclusion can be reached. The maximum expansion stress can be useful and reliable for evaluation if a given slag is suitable for use in a rigid matrix or not. The concrete cylinders made with the slag conforming with the criterion deduced is volumetrically stable under both autoclave test and water soaking for long term curing.

The body or expansion force test using a universal testing machine and autoclave disruption ratio test can be used together to evaluate the volumetrically expansive characteristics of a slag sample particularly when the slag is used as coarse aggregates under constrained environment. The equations deduced can be used to convert the body or expansion force of bulk slag sample to the expansion force of a single slag particle. From the visual observation on the concrete specimens containing the three selected slag samples after rigorous autoclave tests, the expansion forces and 
tension stresses of the steel slag samples, usability criteria for the use of coarse steel slag in concrete established based on steel slag concrete disruption model is promising, although more tests are necessary.

\section{References}

1. Baalamurugan, J.; Kumar, V.G.; Chandrasekaran, S.; Balasundar, S.; Venkatraman, B., Padmapriya; Raja, V.K.B. Utilization of induction furnace steel slag in concrete as coarse aggregate for gamma radiation shielding. Journal of Hazardous Materials 2019, 369(5), 561-568.

2. Brito, J.; Saikia, N. Concrete with recycled aggregates in international codes. Recycled Aggregate in Concrete. Brito \& Saikai (eds.) 2013. New York: Springer.

3. USGS. Natural aggregates - foundation of America's future 2020. (available at http://minerals.usgs.gov/minerals/pubs/commodity/aggregates/ss14497.pdf).

4. Alwaeli, M. Application of granulated lead-zinc slag in concrete as an opportunity to save natural resources. Radiation Physics and Chemistry 2013, 83, 54-60.

5. Anastasiou, E.; Papayianni, I. Criteria for the use of steel slag aggregate in concrete. Measuring, Monitoring and Modeling Concrete Properties, Konsta-Gdoutos, Maria S. (Ed.) 2006. Dordrecht, The Netherlands: Springer, 419-26.

6. Arribas, I.; Santamaria, A.; Ruiz, E.; Ortega-Lopez, V.; Manso, J.M. Electric arc furnace slag and its use in hydraulic concrete. Construction and Building Materials 2015, 90, 68-79.

7. Beshr, H.; Almusallam, A.A.; Maslehuddin, M. Effect of coarse aggregate quality on the mechanical properties of high strength concrete. Construction and Building Materials 2003, 17, 97-103.

8. González-Ortega, M.A.; Cavalaro, S.H.P.; Rodríguez de Sensale, G.; Aguado, A. Durability of concrete with electric arc furnace slag aggregate, Construction and Building Materials 2019, 217, 543-556. https://doi.org/10.1016/j.conbuildmat.2019.05.082

9. Papayianni, I.; Anastasiou, E. Utilization of electric arc furnace steel slags in concrete products. Proceedings of the 6th European Slag Conference, October 20-22nd, 2010, Madrid, Spain.

10. Polanco, J.A.; Manso, J.M.; Jesús, S.; González, J. J. Strength and Durability of Concrete Made with Electric Steelmaking Slag. ACI Materials Journal 2011, 108(2), 196-203.

11. Sinha, H.M. Experimental investigation in utilization of basic oxygen furnace steel slag in concrete. International Journal of Research in Engineering and Applied Sciences 2014, 2(2), 1-4.

12. Subramani, T.; Ravi, G. Experimental Investigation of coarse aggregate with steel slag in concrete. IOSR Journal of Engineering 2015, 5(5), 64-73.

13. Sumi, N.; Malathy, R. Experimental investigation on effect of fly ash and steel slag in concrete pavements. International Journal of Research in Engineering \& Technology 2013, 1(2), 117-124.

14. Zareei, S.A.; Ameri, F.; NasrollahBahrami, N.; Shoaei, P.; Moosaei, H.R.; Niloofar Salemi, N. Performance of sustainable high strength concrete with basic oxygen steel-making (BOS) slag and nano-silica, Journal of Building Engineering, 2019, 25, https://doi.org/10.1016/j.jobe.2019.100791

15. Santamaría, A.; Orbe, A.; Losañez, M.M.; Skaf, M.; Ortega-Lopez, V.; González, J.J. Self-compacting concrete incorporating electric arc-furnace steelmaking slag as aggregate. Materials \& Design 2017, 115, 179193. https://doi.org/10.1016/j.matdes.2016.11.048

16. Fronek, B.; Bosela, P.; Delatte, N. Steel slag aggregate used in portland cement concrete U.S. and international perspectives. Journal of the Transportation Research Board, 2012, 2267, 37-42.

17. Martauz, P.; Vaclavik, V.; Cvopa, B. The use of steel slag in concrete. IOP Conference Series: Earth and Environmental Science, Volume 92, 1st International Conference on Advances in Environmental Engineering (AEE 2017) 28-30 November 2017, Ostrava, Czech Republic.

18. Maslehuddin, M.; Naqvi, A.; Mohammed, I.; Kalakada, Z. Radiation shielding properties of constate with electric arc furnace slag aggregates and steel shots. Annals of Nuclear Energy 2013, 53, 192-196. DOI: 10.1016/j.anucene.2012.09.006 